\title{
Communication
}

\section{A Simple Design of Compact Size UWB Microstrip Antennas with Improved Performance}

\author{
Mohamed Mahmoud Abdelwahab ${ }^{1}$, Ali Mohamed Gomaa ${ }^{2}$, Mahmoud Abdelhaliem Mohana ${ }^{3}$, \\ Moataza Abdelhamied Hindy ${ }^{4}$ \\ ${ }^{1}$ Department of Electrical and Computer Engineering, Higher Technological Institute (HTI), $10^{\text {th }}$ of Ramadan City, Egypt \\ ${ }^{2}$ Faculty of Engineering, Electrical Engineering Department, Benha University, Cairo, Egypt \\ ${ }^{3}$ Seismology Department, National Research Institute of Astronomy and Geophysics (NRIAG), Helwan, Egypt \\ ${ }^{4}$ Microstrip Department, Electronics Research Institute, Giza, Egypt

\section{Email address:} \\ engmohmah1961@gmail.com (M. M. Abdelwahab),dr_alygomaa@yahoo.com(A. M. Gomaa),mahmoud2746@yahoo.com (M. A. Mohana), \\ m1_hendi@yahoo.com (M. A. Hindy)
}

\section{To cite this article:}

Mohamed Mahmoud Abdelwahab, Ali Mohamed Gomaa, Mahmoud Abdelhaliem Mohana, Moataza Abdelhamied Hindy. A Simple Design of Compact Size UWB Microstrip Antennas with Improved Performance. Advances in Wireless Communications and Networks.

Vol. 3, No. 5, 2017, pp. 50-56. doi: 10.11648/j.awcn.20170305.11

Received: June 25, 2017; Accepted: July 14, 2017; Published: August 9, 2017

\begin{abstract}
A compact size ultra-wideband (UWB) microstrip antenna with improved performance is proposed in this communication. In this article, the design of the antenna, which is based on the interaction between the circular patch and the rectangular slot cutting in the metal ground plane, as a result the required starting frequency can be achieved due the coupling between the metal ground plane and patch. UWB microstrip antenna is studied and designed using computer simulation. For verification of simulation results, the antenna is fabricated and measured. The simulation and measured results as reflection coefficient and radiation pattern are presented. Its measured results indicate that the proposed antennas achieve UWB from 1.49 $\mathrm{GHz}$ up to $18 \mathrm{GHz}$ with improved the radiation pattern performance in the upper frequency range(up to $10 \mathrm{GHz}$ ). Proposed antenna achieve many wireless services including wireless local area (WLAN 2.5 or 5.6 GHz), GSM (1.71-1.88 GHz), PCS (1.93-1.99 GHz), Multiband GNNs, UWB (3.1-10.6 GHz), and for see through wall and concrete application.
\end{abstract}

Keywords: Circular Patch Rp, Metal Ground Plane, Rectangular Slot, UWB, Radiation Pattern Uniformity

\section{Introduction}

A different UWB antenna has been studied because of its superior performance characteristics; those include a more compact size, lower profile, and simple structure, which lead to lower cost, easy fabrication and convenient integration with monolithic RF circuits [1]. Many researchers have been reported to achieve the developments of many different wireless communications standards, as the global positioning system (GPS), worldwide interoperability for microwave access (WiMAX), and wireless area network (WLAN). The main problem about UWB antenna is the radiation pattern degradation in the upper of the UWB frequency range as well as compact size. Different UWB antennas has been designed to solve the main problems, such as electromagnetic band gap
(EBG) ground [2] and gate-like [3], [4] structures in the same plane as the radiating elements, and stacked patches [6] and dielectric resonators above them [5]. An optimal microstrip-fed monopole antenna with two F-shaped slot radiators have been proposed for compact size, good tri-band operating bandwidth, and stable radiation patterns [7].

Design of WLAN/LTE/UWB antenna by introducing a ground - cooperative radiating structure (GCRS) into the metal ground plane of a defected hexagonal monopole antenna (HMA) improve the performance of planar ultra-wideband monopole antennas to have stable omnidirectional radiation patterns, much more compact size, and boarder bandwidth [8]. An arc shaped slot is etched into the radiating patch of a standard compact elliptically shaped UWB monopole antenna, which produces broadside realized gain values, above 2.13 $\mathrm{dBi}$ over the entire UWB frequency range as well as improves 
the radiation pattern performances in the upper frequency range and compact size $0.342 \lambda_{0} \times 0.231 \lambda_{0}$ where $\lambda_{0}$ indicates the free space wavelength [9].

In this communication, a simple UWB microstrip antenna is shown in figure 1. The antenna consists of circular patch in front of rectangular slot cutting in metal ground plane. Figure 1a illustrates the top side of board materials; a circular patch of radius $\mathrm{Rp}$ is positioned at the terminal microstrip feeding line to match a $50 \Omega$ standard source. Figure $1 \mathrm{~b}$ illustrates the bottom side of board materials, the metallic ground plane is designed with a rectangular slot of dimensions Ls and Ws. Circular patch operates as an exciter and modified ground plane as a radiator. It will be demonstrated that a rectangular slot effectively tunes the mutual coupling between the circular patch and the ground plane over a very large frequency range to achieve UWB impedance matching as well as improve the stability of the radiation patterns at the higher portion of the UWB frequency range.

\section{Basic Design Rules}

a) A circular patch excites a modified ground plane with rectangular slot as a radiator. A rectangular slot effectively tunes the mutual coupling between the circular patch and the ground plane over a very large frequency range to achieve UWB impedance matching.

b) We use tapered transmission line to improve the impedance bandwidth with respect to the $-10 \mathrm{~dB}$ criterion, the requirement is a transition between the input impedance of radiator and a $50 \Omega$ standard source.

\section{Parametric Studies and Optimization}

The operating principle of the antenna is studied by using the CST 2015 software in two cases. The parametric antenna has been optimized to achieve good performance, impedance matching S11 and enhancement uniform far field radiation gain pattern.

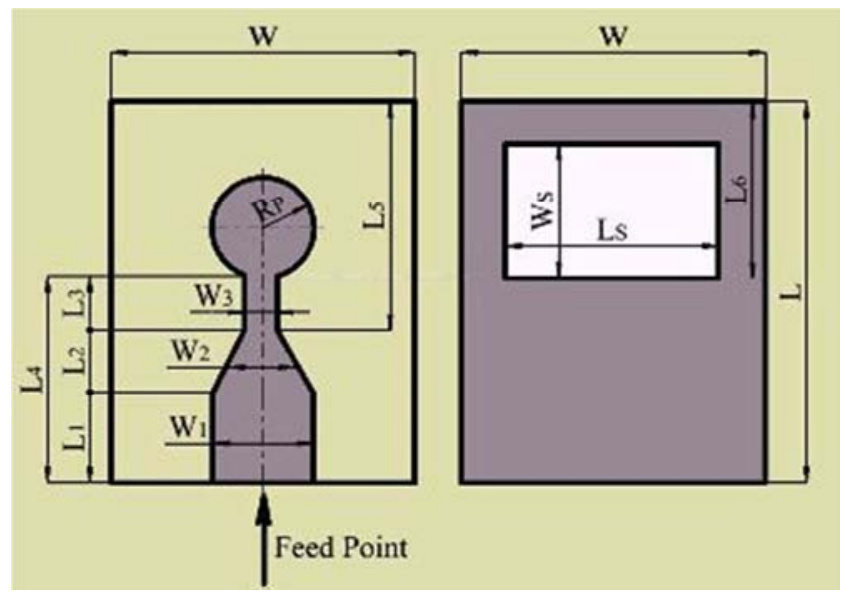

(a)

(b)

Figure 1. Design Layout of the Proposed Antennas. (a) Top View. (b) Metal Ground Plane.

\subsection{Case-1}

Figure 2 illustrates the shape of proposed antennas in case-1. In this case as illustrated in Figure $2 b$ the bottom side of board material is designed to achieve approximately infinite metallic ground plane. Table 1 illustrates the optimized dimensions of the proposed antenna using a substrate of $\in_{\mathrm{r}}=2.2$, and thickness $=1.57 \mathrm{~mm}$. To illustrate the effect of the modified metal ground plane cutting by rectangular slot on the resonating property of the antenna, the simulations were carried out in four optimized construction. Figure 3 indicates the simulation results for different antenna description. As can be seen in table- 2 the impedance matching bandwidth with different area of metal ground plane depends on the tuning between the dimensions of rectangular slot and patch radius Rp.

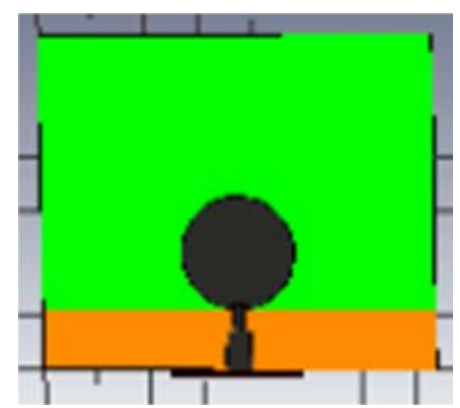

(a)

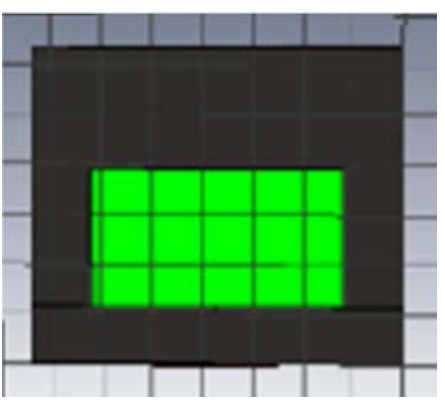

(b)

Figure 2. Proposed Antennas in case-1. (a)Top View. (b) Metal Ground Plane.

Table 1. Antenna Description.

Metal ground plane area $44 \times 41 \mathrm{~mm}^{2}$

\begin{tabular}{lllllll}
\hline $\mathbf{W} \times \mathbf{L}$ & $\mathbf{R p}$ & $\mathbf{L s}$ & $\mathbf{W s}$ & $\boldsymbol{\varepsilon}_{\mathbf{r}}$ & $\mathbf{W 1}$ & $\mathbf{W 2}$ \\
\hline $44 \times 41 \mathrm{~mm}^{2}$ & $6 \mathrm{~mm}$ & 31 & 16 & 2.2 & 4.77 & 4.2 \\
W3 & L1 & L2 & L3 & L4 & L5 & L6 \\
2.5 & 4 & 2 & 4 & 10 & 35 & 31 \\
\hline
\end{tabular}

Metal ground plane area $54 \times 48 \mathrm{~mm}^{2}$

\begin{tabular}{lllllll}
\hline $\mathbf{W} \times \mathbf{L}$ & Rp & Ls & Ws & $\boldsymbol{\varepsilon}_{\mathbf{r}}$ & W1 & W2 \\
\hline $54 \times 48 \mathrm{~mm}^{2}$ & 8 & 38 & 20 & 2.2 & 4.77 & 4.2 \\
W3 & L1 & L2 & L3 & L4 & L5 & L6 \\
2 & 4 & 2 & 4 & 10 & 42 & 38 \\
\hline
\end{tabular}

Metal ground plane area $64 \times 56 \mathrm{~mm}^{2}$

\begin{tabular}{lllllll}
\hline $\mathbf{W} \times \mathbf{L}$ & $\mathbf{R p}$ & Ls & $\mathbf{W s}$ & $\boldsymbol{\varepsilon}_{\mathbf{r}}$ & $\mathbf{W 1}$ & $\mathbf{W 2}$ \\
\hline $64 \times 56 \mathrm{~mm}^{2}$ & 9 & 45 & 24 & 2.2 & 4.77 & 4.2 \\
$\mathrm{~W} 3$ & L1 & L2 & L3 & L4 & L5 & L6 \\
2 & 4 & 2 & 4 & 10 & 49 & 45 \\
\hline
\end{tabular}


Metal ground plane area $74 \times 63 \mathrm{~mm}^{2}$

\begin{tabular}{lllllll}
\hline $\mathbf{W} \times \mathbf{L}$ & $\mathbf{R p}$ & $\mathbf{L s}$ & $\mathbf{W s}$ & $\boldsymbol{\varepsilon}_{\mathbf{r}}$ & $\mathbf{W 1}$ & $\mathbf{W 2}$ \\
\hline $74 \times 63 \mathrm{~mm}^{2}$ & 11 & 50 & 27 & 2.2 & 4.77 & 4.2 \\
$\mathrm{~W} 3$ & L1 & L2 & L3 & L4 & L5 & L6 \\
2 & 4 & 3.5 & 4 & 10 & 55.5 & 52 \\
\hline
\end{tabular}
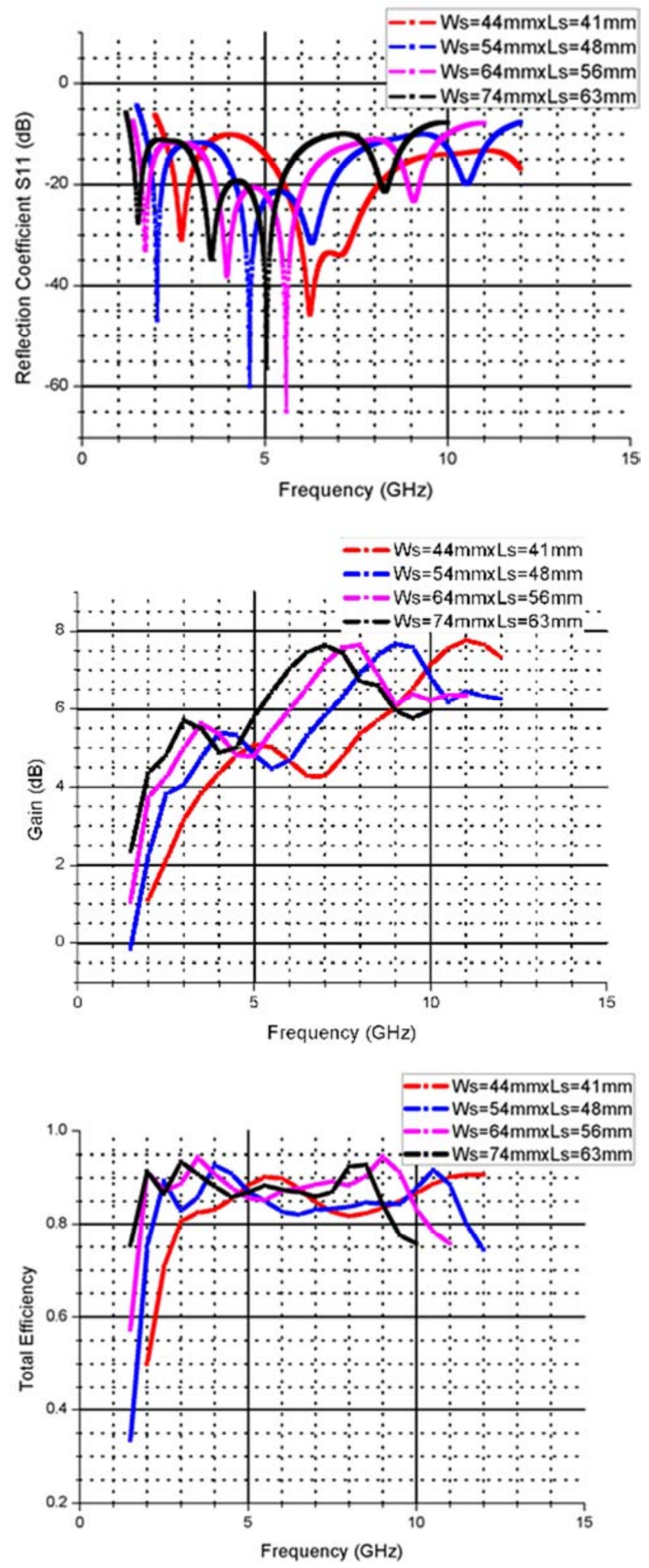

Figure 3. Simulated Results of Proposed Antennas (case-1).
Table 2. Simulated Results of Case-1.

\begin{tabular}{lll}
\hline Antenna Description & $\begin{array}{l}\text { Operating } \\
\text { Frequency }(\mathbf{G H z})\end{array}$ & $\begin{array}{l}\text { Max Gain }(\mathrm{dB}) \text { over } \\
\text { Frequency }\end{array}$ \\
\hline $\begin{array}{l}\mathrm{W}=44 \mathrm{~mm}-\mathrm{L}=41 \mathrm{~mm} \\
\mathrm{Ls}=31 \mathrm{~mm}-\mathrm{Ws}=16 \mathrm{~mm}\end{array}$ & 2.2 up to 12 & 7.75 \\
$\begin{array}{l}\mathrm{W}=54 \mathrm{~mm}-\mathrm{L}=48 \mathrm{~mm} \\
\mathrm{Ls}=38 \mathrm{~mm}-\mathrm{Ws}=20 \mathrm{~mm}\end{array}$ & 1.7 up to 11.4 & 7.75 \\
$\begin{array}{l}\mathrm{W}=64 \mathrm{~mm}-\mathrm{L}=56 \mathrm{~mm} \\
\mathrm{Ls}=45 \mathrm{~mm}-\mathrm{Ws}=24 \mathrm{~mm}\end{array}$ & 1.5 up to 10 & 7.75 \\
$\begin{array}{l}\mathrm{W}=74 \mathrm{~mm}-\mathrm{L}=63 \mathrm{~mm} \\
\mathrm{Ls}=50 \mathrm{~mm}-\mathrm{Ws}=27 \mathrm{~mm}\end{array}$ & 1.3 up to 9 & 7.75 \\
\hline
\end{tabular}

With these results, we propose to set the starting frequency of proposed antennas using the following steps:

1. Bandwidth is one of the key issues of proposed antenna, since the bandwidth can be tuned by adjusting the slot dimensions. As a result, it can be achieved the starting frequency according to the slot dimensions.

2. The starting frequency can be approximately calculated by:

$$
\mathrm{fst}_{\mathrm{st}}=\frac{c}{2(\boldsymbol{L}+W \boldsymbol{S}) \sqrt{\varepsilon_{\mathrm{r}}}}
$$

And $\mathrm{Ls}_{\mathrm{s}}=0.7 \mathrm{~W}, \mathrm{~W}_{\mathrm{s}}=0.35 \mathrm{~W}, \mathrm{~L} 6=0.7 \mathrm{~W}$, and $\mathrm{Rp}=0.21 \mathrm{Ls}$ Since,

a) $\mathrm{c}$ is the velocity of light.

b) Ls, Ws are the slot dimensions.

c) $\varepsilon_{r}$ is the relative permittivity.

\subsection{Case-2}

Figure 4 illustrates the construction of proposed antennas (case-2) with reduced substrate dimensions. In this case as illustrated in Figure $4 \mathrm{~b}$ the bottom side of board material is designed with reduced metallic ground plane area. Table 3 illustrates the optimized dimensions of the proposed antenna using a substrate of $\in_{\mathrm{r}}=2.2$, and thickness $=1.57 \mathrm{~mm}$. To illustrate the effect of reduced modified metal ground plane cutting by rectangular slot on the resonating property of the antenna, the simulations were carried out in four optimized construction. Figure 5 indicates the simulation results for different antenna description. Table-4 illustrates the simulation results.

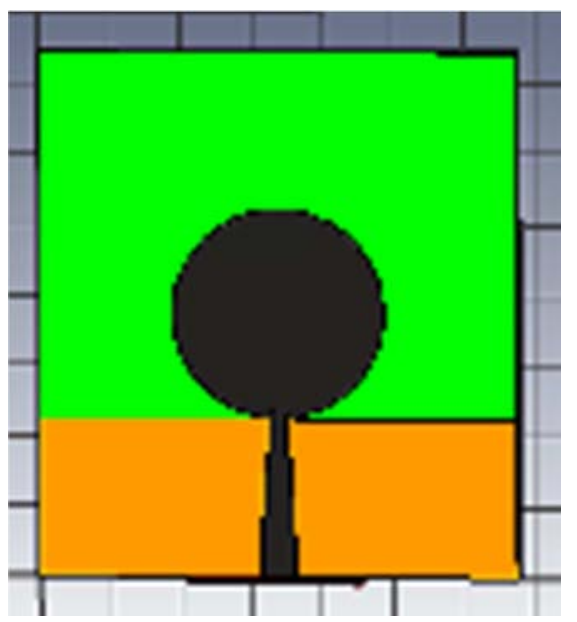

(a) 


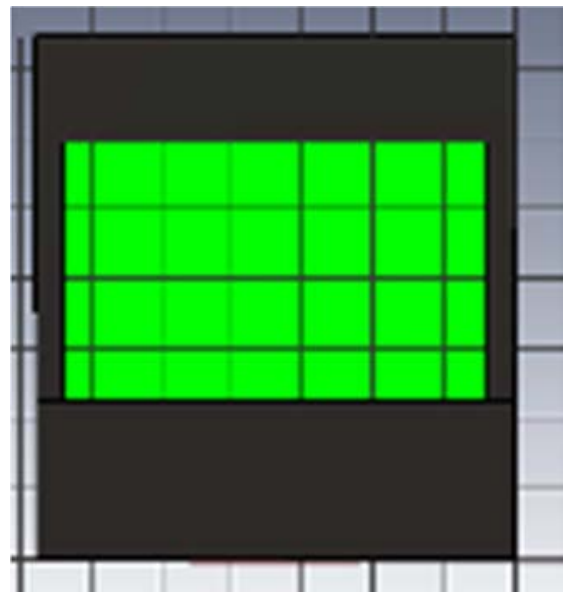

(b)

Figure 4. Proposed Antennas with Reduced Substrate Dimensions. (a) Top View. (b) Metal Ground Plane.

Table 3. Antenna Description.

Metal ground plane area $21.6 \times 27.66 \mathrm{~mm}^{2}$

\begin{tabular}{lllllll}
\hline $\mathbf{W} \times \mathbf{L}$ & $\mathbf{R p}$ & $\mathbf{L s}$ & $\mathbf{W s}$ & $\boldsymbol{\varepsilon}_{\mathbf{r}}$ & $\mathbf{W 1}$ & $\mathbf{W 2}$ \\
\hline $21.6 \times 27.66 \mathrm{~mm}^{2}$ & $5 \mathrm{~mm}$ & 20.5 & 11.4 & 2.2 & 4.77 & 2.8 \\
$\mathrm{~W} 3$ & L1 & L2 & L3 & L4 & L5 & L6 \\
2.699 & 4 & 1 & 4 & 9 & 22.66 & 18.66 \\
\hline
\end{tabular}

Metal ground plane area $29.5 \times 37 \mathrm{~mm}^{2}$

\begin{tabular}{lllllll}
\hline $\mathbf{W} \times \mathbf{L}$ & $\mathbf{R p}$ & $\mathbf{L s}$ & $\mathbf{W s}$ & $\boldsymbol{\varepsilon}_{\mathbf{r}}$ & $\mathbf{W 1}$ & $\mathbf{W} 2$ \\
\hline $29.5 \times 37 \mathrm{~mm}^{2}$ & $7 \mathrm{~mm}$ & 27.6 & 16.7 & 2.2 & 4.77 & 4.2 \\
$\mathrm{~W} 3$ & L1 & L2 & L3 & L4 & L5 & L6 \\
2.699 & 4 & 3 & 4 & 11 & 30 & 26 \\
\hline
\end{tabular}

Metal ground plane area $36 \times 45 \mathrm{~mm}^{2}$

\begin{tabular}{lllllll}
\hline $\mathbf{W} \times \mathbf{L}$ & $\mathbf{R p}$ & $\mathbf{L s}$ & $\mathbf{W s}$ & $\boldsymbol{\varepsilon}_{\mathbf{r}}$ & $\mathbf{W 1}$ & $\mathbf{W 2}$ \\
\hline $36 \times 45 \mathrm{~mm}^{2}$ & $9 \mathrm{~mm}$ & 33.5 & 21 & 2.2 & 4.77 & 4.2 \\
$\mathrm{~W} 3$ & L1 & L2 & L3 & L4 & L5 & L6 \\
2.699 & 4 & 3 & 4 & 11 & 44.5 & 34 \\
\hline
\end{tabular}

Metal ground plane area $68 \times 74.5 \mathrm{~mm}^{2}$

\begin{tabular}{lllllll}
\hline $\mathbf{W} \times \mathbf{L}$ & $\mathbf{R p}$ & $\mathbf{L s}$ & $\mathbf{W s}$ & $\boldsymbol{\varepsilon}_{\mathbf{r}}$ & $\mathbf{W 1}$ & $\mathbf{W 2}$ \\
\hline $68 \times 74.5 \mathrm{~mm}^{2}$ & $15 \mathrm{~mm}$ & 60 & 37 & 2.2 & 4.77 & 3.2 \\
$\mathrm{~W} 3$ & L1 & L2 & L3 & L4 & L5 & L6 \\
2.3999 & 5 & 12.5 & 5 & 22.5 & 57 & 52 \\
\hline
\end{tabular}

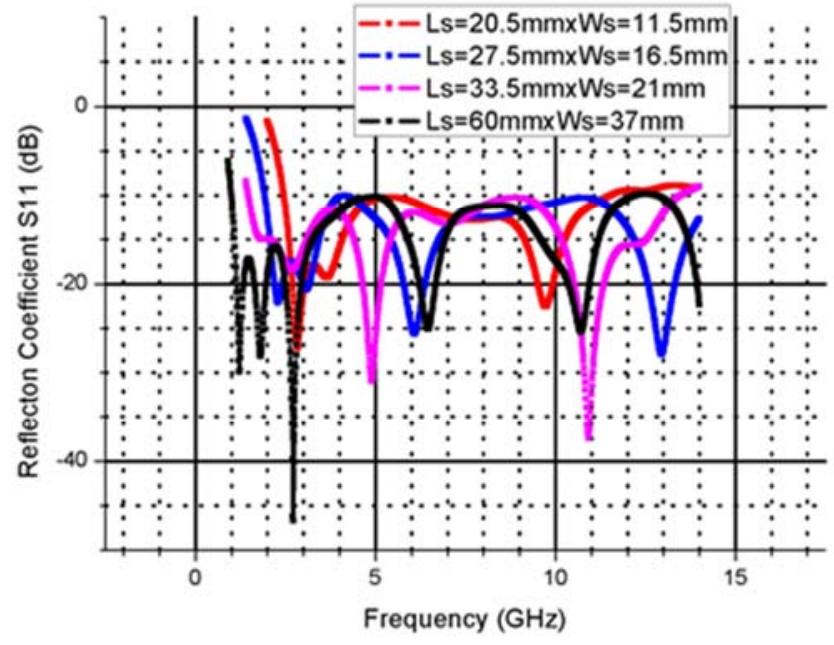

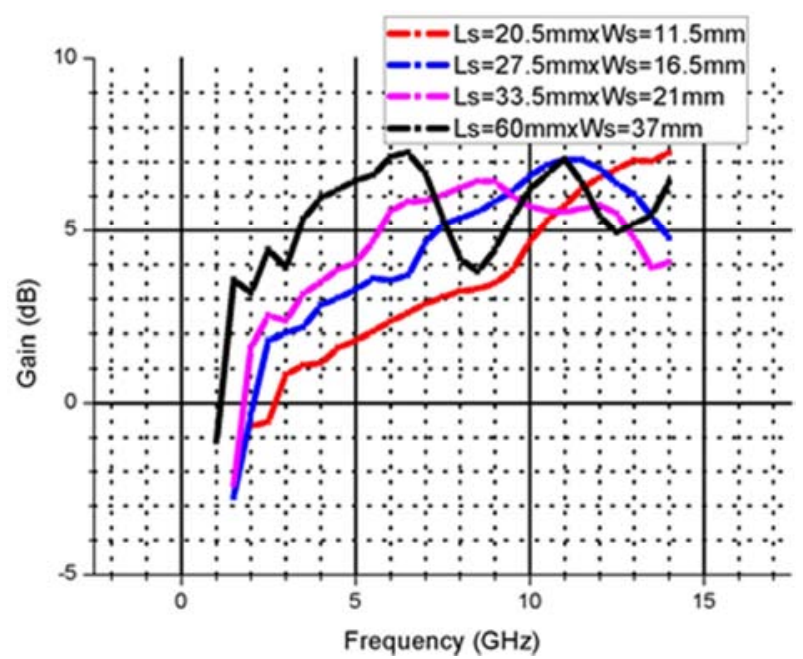

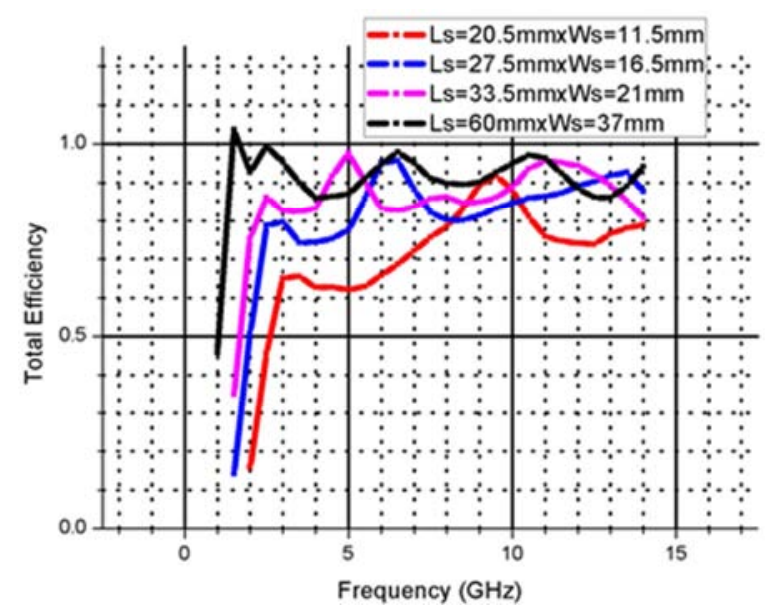

Figure 5. Simulated Results of Proposed Antenna with Reduced Size (case-2).

Table 4. Simulated Results of Case-2.

\begin{tabular}{|c|c|c|}
\hline Antenna Description & $\begin{array}{l}\text { Operating } \\
\text { Frequency(GHz) }\end{array}$ & $\begin{array}{l}\text { Max Gain (dB) over } \\
\text { Frequency }\end{array}$ \\
\hline $\begin{array}{l}\mathrm{W}=22 \mathrm{~mm}-\mathrm{L}=27 \mathrm{~mm} \\
\mathrm{Ls}=21 \mathrm{~mm}-\mathrm{Ws}=11.5 \mathrm{~mm}\end{array}$ & 2.45 up to 11.5 & $y_{2}$ \\
\hline $\begin{array}{l}\mathrm{W}=30 \mathrm{~mm}-\mathrm{L}=37 \mathrm{~mm} \\
\mathrm{Ls}=28 \mathrm{~mm}-\mathrm{Ws}=17 \mathrm{~mm}\end{array}$ & 1.94 up to 14 & 7 \\
\hline $\begin{array}{l}\mathrm{W}=36 \mathrm{~mm}-\mathrm{L}=45 \mathrm{~mm} \\
\mathrm{Ls}=34 \mathrm{~mm}-\mathrm{Ws}=21 \mathrm{~mm}\end{array}$ & 1.5 up to 14 & 7 \\
\hline $\begin{array}{l}\mathrm{W}=68 \mathrm{~mm}-\mathrm{L}=74.5 \mathrm{~mm} \\
\mathrm{Ls}=60 \mathrm{~mm}-\mathrm{Ws}=37 \mathrm{~mm}\end{array}$ & 1 up to 14 & 7 \\
\hline
\end{tabular}

With these results, the starting frequency can be approximately calculated as in case- 1 .

\section{Practical Result and Discussion}

To validate the basic design rule, a prototype of the proposed antenna with dimensions given in table- 3 of $\mathrm{Rp}=9 \mathrm{~mm}$ is designed and fabricated as shown in Figure 6. Manufacturing and measurement of reflection coefficient S11 parameters were carried out in National Telecommunication Institute and radiation pattern was measured in the antenna lab (operating frequency from $1 \mathrm{GHz}$ up to $10 \mathrm{GHz}$ ) in the microwave engineering department, Faculty of Engineering, Ain Shams University. Figures 7 shows the reflection coefficient S11 
which indicates that the proposed antenna achieves good impedance matching with starting frequency $1.49 \mathrm{GHz}$ up to $18 \mathrm{GHz}$. Figure 8 illustrate better radiation pattern up to $10 \mathrm{GHz}$.

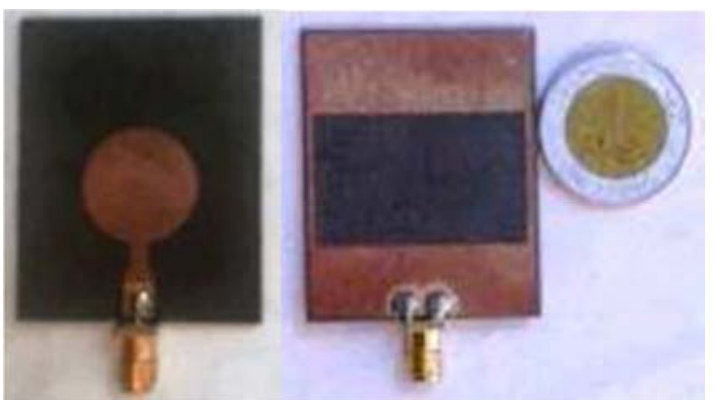

Figure 6. Photograph of the Proposed Antenna.

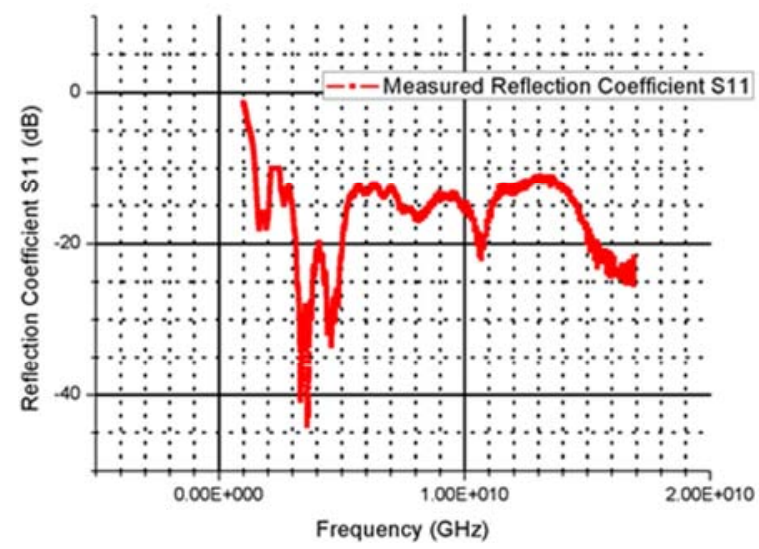

Figure 7. Measured Reflection Coefficient S11.
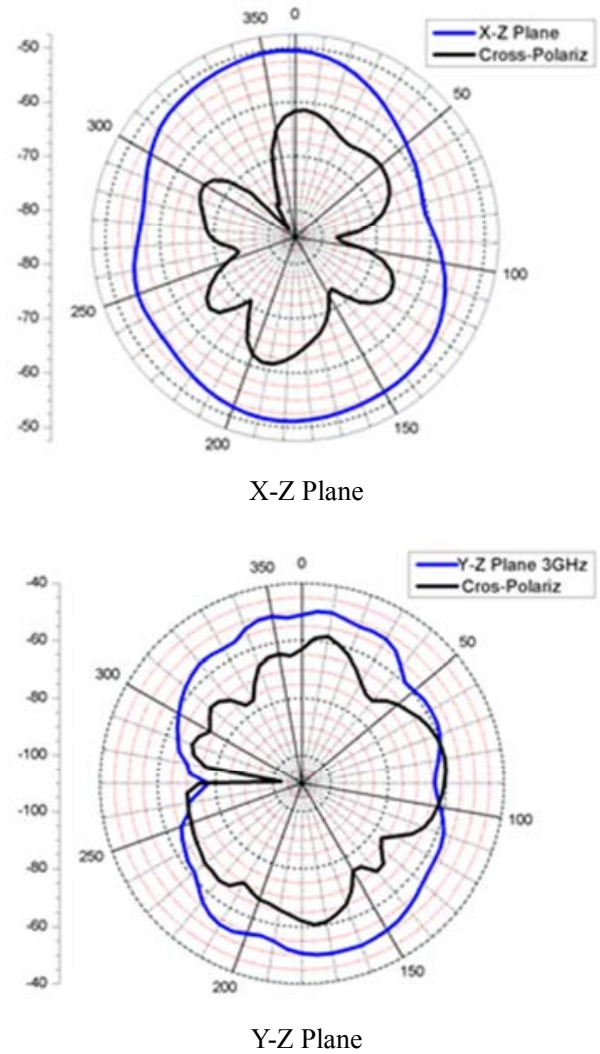

(a)
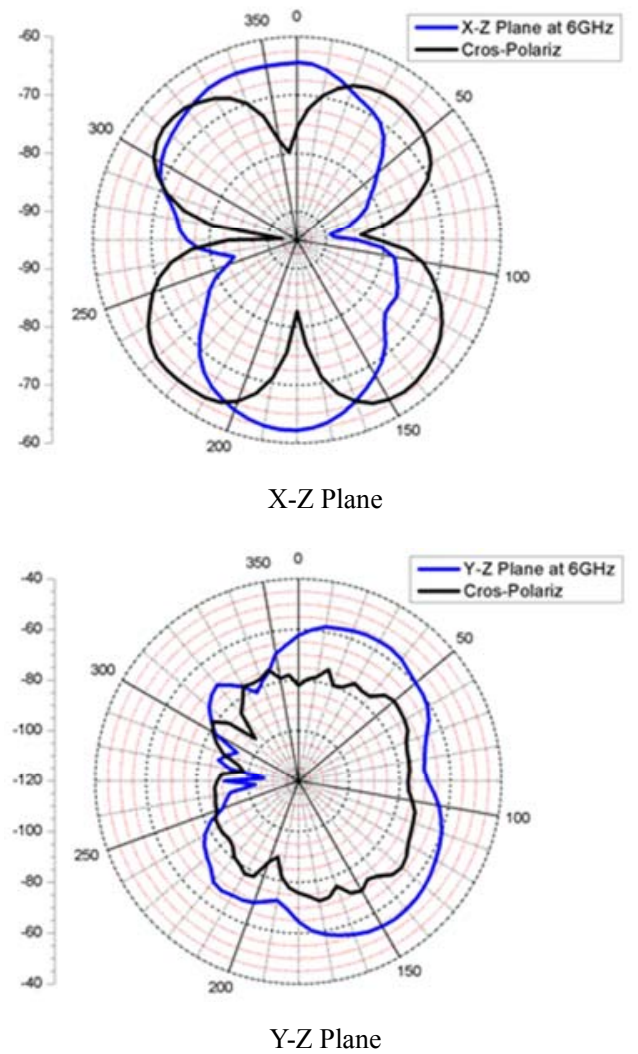

(b)
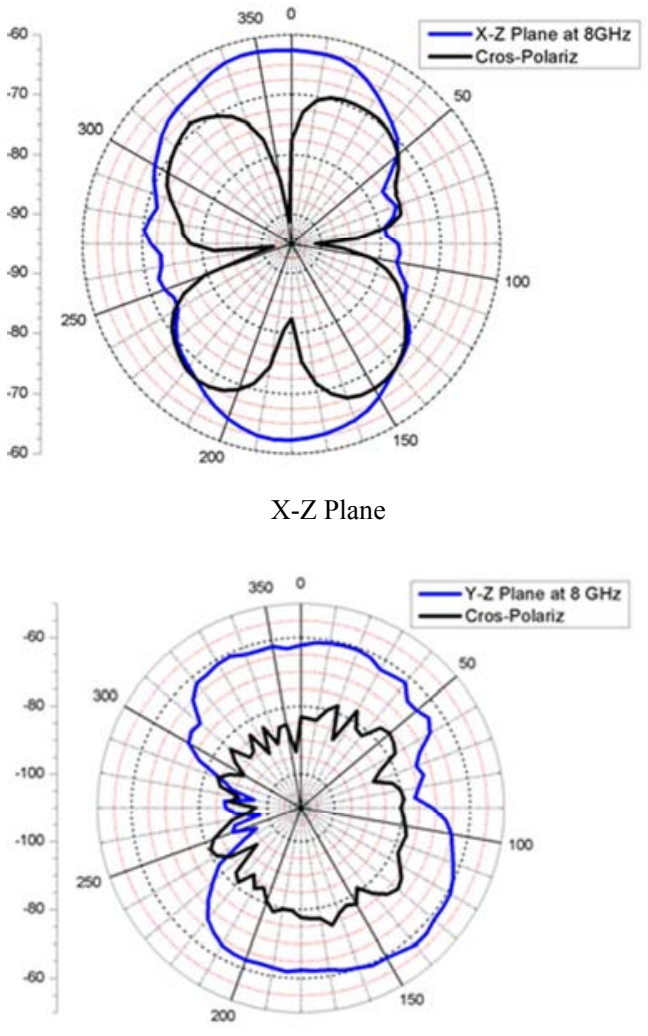

Y-Z Plane

(c) 

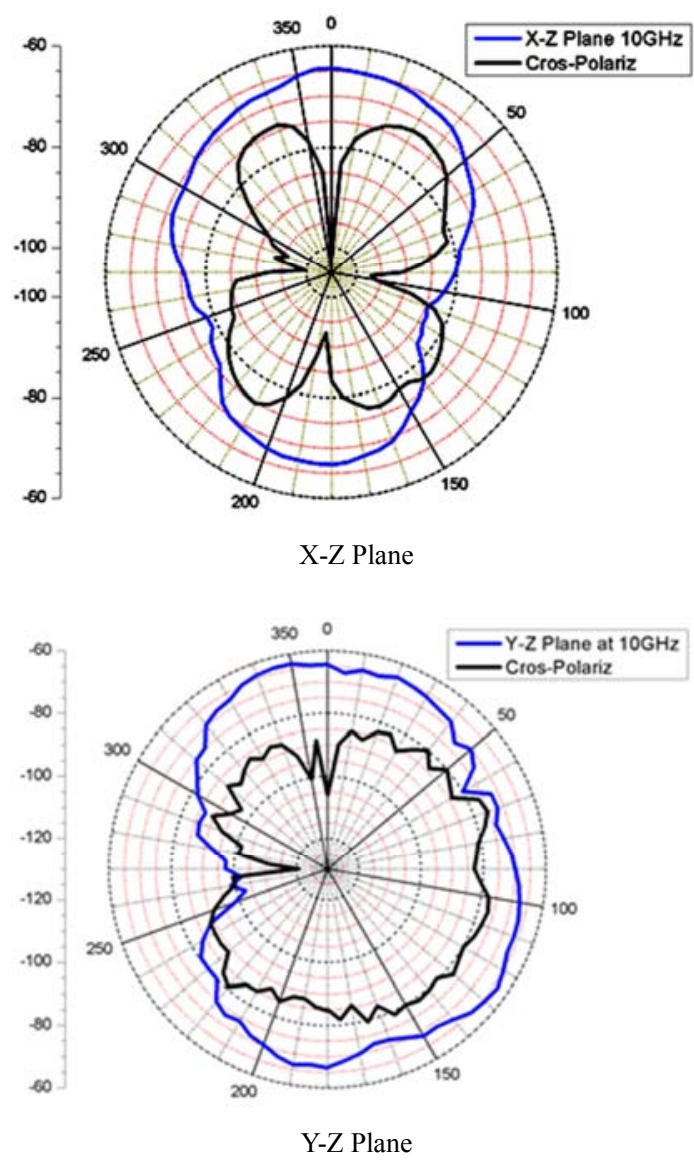

(d)

Figure 8. Measured Radiation Pattern. (a) at $3 \mathrm{GHz}$. (b) at $6 \mathrm{GHz}$. (c) at 8 GHz. (d) at $10 \mathrm{GHz}$

Table-5 illustrates the comparison between the proposed antennas with the UWB antennas reported in [8], [9], [10], [11], [12]. As can be seen, the proposed antenna provide a broaden impedance matching bandwidth with improved the realized gain values, and the lower edge frequency than reported in [8], [9], [10], [11], [12].

Table 5. Comparison of UWB Antennas.

\begin{tabular}{llll}
\hline Antenna description & $\begin{array}{l}\text { Bandwidth } \\
(\mathbf{G H z})\end{array}$ & $\begin{array}{l}\text { Max Gain } \\
(\mathbf{d B})\end{array}$ & Size $\left(\mathbf{m m}^{2} / \boldsymbol{\lambda}_{\mathbf{0}}{ }^{2}\right)$ \\
\hline Proposed Antennas & $\begin{array}{l}1.49-18 \\
(168 \%)\end{array}$ & 7.2 & $0.178 \times 0.22 \lambda_{0}{ }^{2}$ \\
Hexagonal Monopole[8] & $\begin{array}{l}2.38-11.8 \\
(133 \%)\end{array}$ & 5.6 & $0.21 \times 0.25 \lambda_{0}{ }^{2}$ \\
arc shaped slot[9] & $\begin{array}{l}2.7-10.8 \\
(102 \%)\end{array}$ & 6 & $0.22 \times 0.32 \lambda_{0}{ }^{2}$ \\
Integrated antenna[10] & $\begin{array}{l}3.2-10.9 \\
(109 \%)\end{array}$ & 5.1 & $0.54 \times 0.65 \lambda_{0}{ }^{2}$ \\
Spanner Monopole[11] & $\begin{array}{l}2.95-11.8 \\
(129 \%)\end{array}$ & 7 & $0.3 \times 0.51 \lambda_{0}{ }^{2}$ \\
CPW-fed slot antenna[12] & $\begin{array}{l}3.1-11.1 \\
(113 \%)\end{array}$ & 5 & $0.27 \times 0.27 \lambda_{0}{ }^{2}$ \\
\hline
\end{tabular}

Since $\lambda_{\circ}$ is the free space wavelength.

\section{Conclusion}

In this article, the operating principle of the antenna is studied in two cases to discuss the effect of metal ground plane area on antenna performance. As can be seen in case -2, the antenna exhibit reasonable performance over the entire frequency range with compact size but in case- 1 the realized gain is enhanced in the lower portion of the UWB frequency range with slightly enhancement in that upper portion than in case -2 . We present the design process to fabricate metal ground plane cutting by rectangular slot as a radiator with a circular patch as exciter, and testing of antenna with improved broadside - realized gain values above $3 \mathrm{~dB}$ over the entire UWB frequency range, as well as lowered the lower edge of the impedance bandwidth. By tuning the dimensions of the rectangular slot and circular patch radius, a broaden impedance matching was achieved with improved radiation pattern uniformity as well as compact size. The simulation and measured results indicate good performance than the UWB antenna reported in [8], [9], [10], [11], [12]. As a result the proposed antenna achieve the developments of many different wireless communications standards, as the global positioning system (GPS), worldwide interoperability for microwave access (WiMAX), and wireless area network (WLAN).

\section{References}

[1] G. Adamiuk, T Zwick, and Wiesbeck, "UWB antennas for communication systems," Proc. IEEE, vol. 100, no. 7, pp. 2308-2321, July.2012.

[2] F. Fereidonny, S. Chamaani, s. A. Mirtaheri, "UWB monopole antenna with stable radiation pattern and low transient distortion," IEEE Antennas Wireless Propagation. Lett, vol. 10, pp. 302-305, Apr. 2011.

[3] G. k. Pandy, H. S. Singh, p. k. Bharti, and M. K. Meshram, "UWB monople antenna with enhanced gain and stable radiation pattern using gate like structures," in proc. Int. Conf. Microw. Photon. (ICMAP'13), 2013, pp. 1-4.

[4] J. Wang and Y. Yin, "Differential - fed UWB microstrip antenna with improved radiation patterns," Electron. Lett; vol. 50, no. 20, pp. 1412-1414, sep. 2014.

[5] K. S. Ryu and A. A. Kishk, "UWB dielectric resonator antenna having consistent omnidirectional pattern and low cross polarization characteristics," IEEE Trans. Antennas Propag., vol. 59, no. 4 pp. 1403-1408, Apr. 2011.

[6] W. Zhang, A. Hoorfar, and C. Thajudeen, "Boresight gain enhancement of an UWB planar monopole antenna," in proc. IEEE Antennas Propag Soc. Int. Symp. (APSURSI' 12, 2012, pp. 1-2.

[7] Anil Kumar Gautam, Lalit Kumar, Binod Kumar Kanaujia, and Kaarumudi Rambabu, "Design of Compact F-Shaped Slot Triple-Band Antenna for WLAN-WiMAX Applications" IEEE Transaction on Antennas and Propagation, vol. 64, NO. 3, pp. 1101-1105, March 2016 .

[8] Deshuang Zhao, Changxing Yang, Min Zhu, and Zhixin Chen, "Design of WLAN/LTE/UWB Antenna with Improved Pattern Uniformity Using Ground-Cooperative Radiating Structure" IEEE Transaction on Antennas and Propagation, vol. 64, NO. 1, pp. 271-276, January 2016. 
[9] Ming-Chun TANG, Ting Shi, and Richard W. Ziolkowski, "Planar Ultra-wideband Antennas with Improved Realized Gain Performance," IEEE Transaction on Antennas and Propagation, vol. 64, NO. 1, pp. 61-69, January 2016.

[10] E. Ebrahimi, J. R. Kelly, and P. S. Hall, "Integrated Wide-Narrowband Antenna for Multi-Standard Radio," IEEE Trans. Antennas Propag., VOL. 59. NO. 7 pp. 2628-2635, Jul 2011.
[11] M. Tapan and D. Santanu, "Microstrip Feed Spanner Shape Monopole Antennas for Ultrawide Band Applications," J. Microw. Optoelectron. Electromagn. Appl., Vol. 12, No. 1, pp. 15-22, Jun. 2013.

[12] V. A. Shmeena, S. Mridula, A. Pradeep, Jacob, A. O. Lindo, and P. Mohanan, "A compact CPW Fed Slot Antenna for Ultra-Wideband Applications," Int. J. Electron. Commun, Vol. 66, pp. 189-194, 2012. 